\title{
Title: A reflective encounter with the fine sand area in a Nursery school setting.
}

Abstract: This paper draws on a model of reflection that involves creating meanings through repeated encounters with evocative objects. Responses to one such evocative object, a twenty second video clip of children playing in the fine sand area, illustrates the 'turning towards' and then 'turning away' from the object to engage with broader themes. Parten's play types are used when analysing children's play in the fine sand area (the evocative object). The focus then turns away to themes of English as a Second Language, messy play, energies of childhood and Foucault's docile bodies. The intention was to integrate loosely formulated research aims relating to quality of the physical environment within the evolving life of the nursery setting to encourage a developing research orientation and reflective disposition. This way of approaching practitioner research is well adapted to a longer term engagement with enduring areas of interest such as developing the potential of the physical environment.

Key words: play, nursery, reflective practice, Parten, EAL, generative social research

\section{Introduction}

The project commenced in December 2013 with preliminary visits to a local Nursery School to discuss the aims and scope of a possible research project with the head teacher. One of the school's particular strengths was its well-resourced, open and expansive physical environment that was frequently changed to meet the needs of the children, both inside and outside. First impressions suggested this was one of the school's major strengths but it was also an area that the head teacher was keen to develop, being a key theme within the Early Years Foundation Stage curriculum. As a starting point attention was focused on the 'enabling environment' (EYFS 2012). However, Claxton \& Carr's (2004) progressive classification of learning environments as prohibiting, affording, inviting and potentiating helps to provide further depth to the concept of enabling environment. The potential of insights from environmental psychology also suggested the value of adopting a more open perspective. The aims that emerged from the initial discussions were loosely formulated but related to developing the potential of the physical environment within the context of the 
characteristics of effective learning and foundation stage learning. There was also the desire to establish a longer term project responsive to ongoing changes within the nursery.

At the commencement of the project it was decided that the Early Childhood Environment Rating Scale (ECERS) was not well suited for evaluating the school's frequently changing physical environment. Moreover, critiques of the ECERS approach have noted that the broad scope and equal weighting of assessment items "may conceal critically important areas of program weakness" (Layzer \& Goodson, 2006, p. 570). The underlying theory of ECERS also introduces a biased perspective on quality e.g. the valuing of "independent play with child-selected materials" without the involvement of the teacher (p. 568). Particular attention is given to questionable psychometric properties such as the step from a 3 to a 5 rating on the scale being smaller than the step between 5 and 7 and; the use of the stop-scoring approach which means that higher scores are not possible if lower scores haven't been achieved. This is based on the questionable assumption that "it is rare for a program to fail on a lower component of an item yet still demonstrate some of the higher-quality practices included in that item" (p. 571). Layzer \& Goodson (2006) also drew attention to evidence suggesting that "raters focus more on the physical aspects of the environment than on the critical interactions that take place there" (p. 570). More recently, research by Gordon et al (2013) also questioned the validity of the ECERS-R scale and highlighted the "surprisingly little empirical evidence of the validity of the ECERS-R instrument to support its widespread use in research and policy contexts" (p. 146). The ECERS approach was also regarded as imposing a preconceived 'top down' structure which gives insufficient attention to specific contexts and experiences of children and practitioners.

The Quality Learning Instrument (QLI) developed by Walsh \& Gardner (2005) drew attention to the value of analysing the child/environment/teacher interactive triangle using a ground up approach. Evaluating the quality of the physical environment in this way starting with children's experience gives more recognition to the 'voice' of the child, which supports a more ethical approach to research in the early-years (Sergeant \& Harcourt 2012). It also supports a more emergent and generative methodology responsive to particular contexts though the nine categories of the QLI still 
impose a predetermined structure to the rating scale. However, any use of rating scales suggests a two dimensional snapshot approach to assessing quality which, while not without value, loses some of the flow of contemplative holistic experience. Insofar as the project aims were loosely formulated and integrated into the unfolding life of the nursery, the QLI therefore also seemed restrictive.

Rather than trying to force fit evaluation into any pre-existing set of criteria it was therefore decided to develop a more holistic and flexible approach.

Having loosely formulated research aims integrated within the evolving life of the nursery setting allows for a developing research orientation and disposition rather than a pre-planned research project. Longer term ongoing reflection can move away from the fast lane of answering pressing research questions to the more contemplative lakeside view including a more unconstrained exploration of experience. Rasberry's (2002 p. 105) evocative phrase the "beautifully serpentine course" (p.105) traced by the research suggests a similar flexibility. An approach utilising the potential of video and multimedia compiled as ethnographic portraits of events and individual children within the setting context and recording unconstrained emergent reflections of participants was therefore considered.

Video can be used in various ways within qualitative research such as for video elicitation where participants are shown the video to elicit responses; for providing data to be analysed through coding or more holistically for producing videographies. Heath et al (2010) drew attention to the value of video data as evidence

“A long standing criticism of ethnography concerns the lack of its 'transparency': critics highlight the difficulties of recovering what the researcher saw and experienced undermining the ability of fellow scholars to form an independent judgment of the quality of the analysis" (p. 7) whereas video "preserves the original record for repeated scrutiny" (p. 6) 
Eisner $\left({ }^{* *}\right)$ and Richardson $\left({ }^{* * *}\right)$ have also noted how traditional research reports can lack vitality. Consequently links to an illustrative extract from the video data have been included in this report so that readers may respond to the data in their own way.

Williams et al (no date) identified and considered an extended range of ethical issues relating specifically to use of multimedia in qualitative research including archiving and storage, data integrity, anonymity and potential for embarrassment. For example, blurring images and disguising voices undermines the evocative potential of multimedia so informed voluntary consent was given to include the video clip and extracted photos in this report.

\section{Methodology}

At the start of the project the concept of 'schema' provided a potentially useful theoretical perspective as one foundation for developing the physical milieu for individual children. The school was already identifying children with different schemas such as transporter, builder, envelopment, scattering, rotation, enclosure (Baker-Jones 2010). It seemed reasonable to develop this further by tracking individual children and recording the way in which the particular physical environment could be developed to enhance their experience and/or learning opportunities. For example, a child with a constructor schema, who was reluctant to play outside, could be encouraged to play outside through being made aware of construction opportunities outside as well as inside. At this early stage in the project the head teacher was keen to use the familiar Leuven Involvement scale (Laevers et al, 2005) to standardise the observational record though other approaches were also considered e.g. the SSAT engagement scale(SSAT 2014) and the Teacher Involvement Scale (Howes \& Stewart, 1987). It was agreed that mapping the setting and monitoring different activity areas as well as general activity would provide potentially useful quantitative and qualitative data e.g. frequency of use, identity of children and how the areas and in-between spaces were being used. However, although rating scales were considered, systematic application of the categories was eschewed in favour of the more open free ranging evocative objects model developed by Barnett (2013). The evocative objects model includes 'turning towards' the object as well as reflecting more widely by 
'turning away' from the object to generate broader associations. What's actually noticed at first becomes the source for thinking more reflectively and feeds an additive process of reflection. Essentially the encounter becomes a 'being-in-relation-to' the object as reflections develop iteratively through repeated encounters with the object over an extended period of time. This generative approach allowed for wider ranging collaborative reflection and an ongoing reflective conversation rather than findings-to-be- applied approach began to emerge. Baker et al's model of conversational learning involves generating and revisiting ideas and concepts through conversation

“...ideas and concepts acquire new meaning as individuals return to the same conversation to question and inquire about their experiences anew" (Baker et al 2002 p.12).

The use of multimedia also suggested the value of an iterative research design as advised by Heath et al (2010) because of the time consuming nature of the video editing process. Ongoing analysis of video footage was able support greater involvement of the staff, who were invited to respond to the data as it was being collected.

Multimedia such as audio and video helps to preserve the integrity of the action in focus. Although inevitably camera angles and choice of shot impose perspective the amount of detail helps to preserve the evocative potential of the data. For example, a movement, gesture or facial expression observed when watching a video clip can recall prior action, events and general understandings. Viewing the action in context can also contribute to the interpretation and evocative potential. A previous research study involving the concept of generative social research (Barnett 2013) had explored the use of Quick Time Virtual Reality (QTVR) and embedded multimedia clips. This generative approach related well to the idea of underpinning the direction of the project with an ongoing reflective conversation. It was therefore decided to produce QTVR views of the setting to provide a framework and evocative visual container for reflecting on the quality of the experience and/or learning opportunities of individual children. Video clips of children and photo evidence were to be embedded into the QTVR views using hyperlinked colour coded flags for individual children. Basic statistical data relating to frequency would then be available and also qualitative data in the 
form of video clips. In order to support ongoing reflection, and add to the depth of the qualitative data, the QTVR and embedded video clips were to be linked to a MySQL database accessible via a password protected internet website. It was hoped that this method would encourage members of staff to view the video clips and record reflections in a more leisurely manner, when they had time available e.g. during an evening or weekend when they were at home. Another advantage of this database was the ability to search and compile the comments using key words. The plan was to use compiled reflections as part of an ongoing identification of issues, themes and opportunities for developing the physical setting.

\section{Setback and changes to the research design}

As typically happens there were several setbacks right from the start and these necessitated changes to the broader research design.

An initial setback was related to difficulties recruiting student volunteers and staff illness. The primary means of data collection through videoing was delayed several months until February 2014 while endeavouring to recruit student volunteers. During this time there were several preliminary visits to the nursery to discuss the project. These visits also enabled staff and children to get used to the project before commencement of the videoing. Although, as is commonly the case in early-years settings, staff frequently took children's photos and recorded brief video clips for the early-years profile, having an outsider in the setting making more extensive use of a video camera is potentially more intrusive. Essentially, getting to know the staff and children during the preliminary visits helped to establish trust prior to the commencement of video data collection as suggested by Heath et al (2010).

In the absence of student volunteers the project proceeded with one video camera being used to track a sample of six children during mainly afternoon periods at weekly and fortnightly intervals. Video cataloguing, editing and transcribing where appropriate is a time consuming process; Heath et al (2010) suggest that one hour of video material may need at least three to five hours transcription 
time. Consequently, although it would have been possible to use a stationary camera pointed at a designated area(s) as well as a roaming camera this would have required an unmanageable amount of processing time. The use of a 360 degree video camera was considered but the physical layout of the nursery and the movement of the children suggested a roaming camera would be more responsive.

It soon became apparent that the plan to embed video clips into QTVR views of the setting was problematic due to the high frequency of changes to the setting. This had not been anticipated at the commencement of the project. The outcome was that even before the first videos were embedded in the QTVR the setting had changed. Nonetheless, the broad layout of the setting was constant throughout the project e.g. although the specific form and activities within the numeracy area changed considerably the essential nature of the areas remained constant i.e. the numeracy area was always the numeracy area. Consequently it was still useful to embed video clips into the QTVRs of the setting. Photos were also added to the QTVR to highlight specific changes though the video clips themselves are a clear record of changes made to the setting during the project.

Another consequence of using video as the primary data collection method related to staff becoming overloaded with videos. By May 2014 more than 100 video clips had been added to the QTVR views. Although the length of the video clips varied from several seconds to several minutes staff were finding it onerous to watch so many videos, particularly with the expectation that they would also add written comments to the MySQL database.

Following discussion with the head teacher it was decided to focus on selected video clips during whole staff meetings, with one staff member typing collective comments during discussion of the videos. A second strategy was also introduced: Individual members of staff were involved in 10-15 minute interviews. During the interviews, video clips were used as evocative objects to generate 
discussion that was then recorded in the MySQL database. These more formal strategies were supplemented by informal conversations.

\section{Results}

\section{The QTVR visual maps}

Figure 1 shows a close up screenshot of a QTVR map of part of the setting. Colour coded circles mark the location of video clips for sample children during different observation periods. The image shows the malleable area, the role-play area, the light room and the left side of the construction area. It's noticeable that the light room and visible construction area have fewer video clips than the malleable and role-play areas. Part of the explanation for this relates to the time of day when the observations were made. As is typical in UK nursery settings some children attend only in the morning or afternoon and most of the observations were from the afternoon sessions. The head teacher emphasised that even for children who stay all day the pattern of behaviour varies between mornings and afternoons. However, the strategy for videoing, editing and selecting video clips was based on the evocative objects model (Barnett, 2013) which involves focusing on interesting events and glancing impressions rather than using a comprehensive sampling approach.

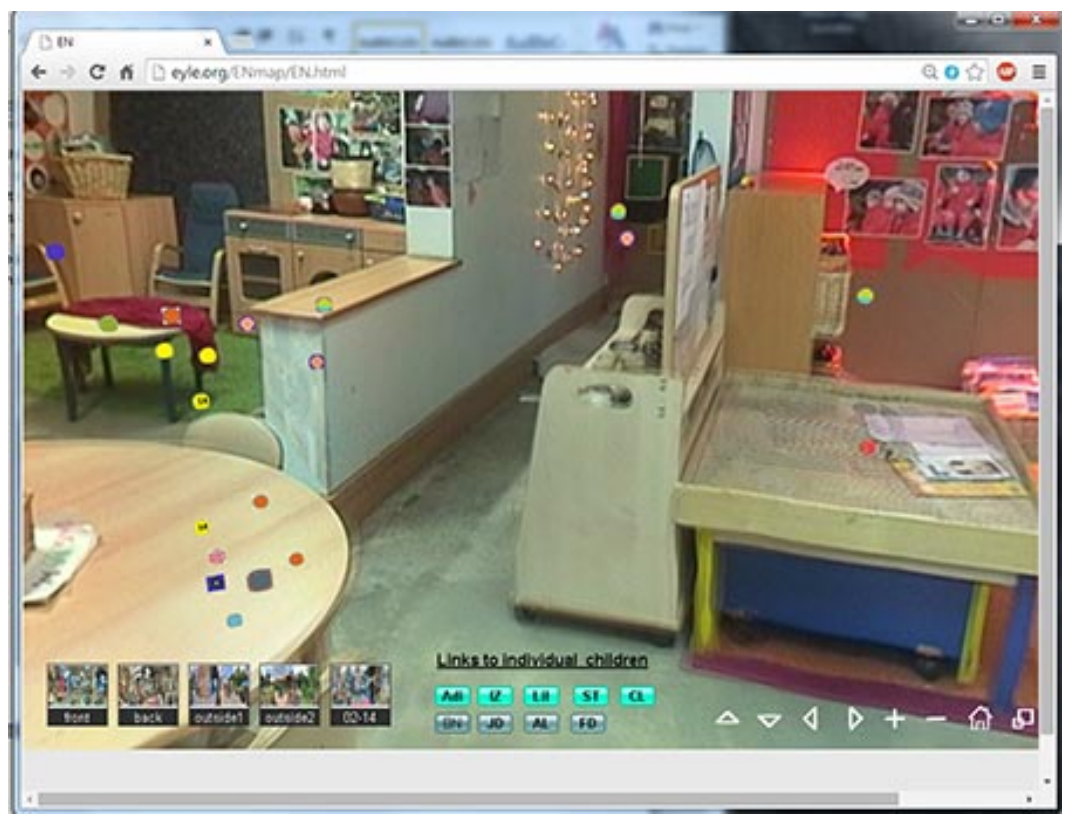


Figure 1

A snapshot of the data up to and including May 2014 is depicted in table 1. This shows the number of video clips for the six sample children in relation to location within the setting. For example, there were 36 video clips for S1 (Referred to as AD - a three and a half year old Polish boy with very limited comprehension of English). The Role play area was located next to the Malleable area and AD's play extended between the two areas (similarly in relation to the Interactive Whiteboard). The number of video clips per child per area shows the range $=0-7$ and mean $=16$ video clips per child. For some of the children the video data on different occasions shows very different behaviour. For example, on one visit BN's behaviour was noticeably solitary and lacking purpose whereas on a subsequent visit BN was sociable and lively. Although the observation visits took place over a period of months, so child development is likely to have occurred during this period, each event retains an evocative potential of its own. Neither the global visual map nor the maps for individual sample children are intended to provide reliable indications of patterns of activity but the accumulation of events may provide a further layer for extending the reflective encounter with the data. In relation to this generative evocative potential, the video clips are a fundamental source of value as talking points, spurs for contemplation and reflective thinking.

A live version of the QTVR global map is available from http://eyle.org/EN1/map.html (Login: messy1 password: messy1) [NB. Links to sample children and the colour coded circles hyperlinked to the embedded video clips have been disabled to preserve the integrity of the project. However readers can add their own reflections to the MySQL database and also search through the reflections of other readers. Please email the author with expressions of interest to request further access.] 


\begin{tabular}{|c|c|c|c|c|c|c|}
\hline Total videos & S1 & JD & $\mathrm{AL}$ & FD & $\mathrm{CL}$ & BN \\
\hline 98 & 36 & 15 & 5 & 7 & 13 & 22 \\
\hline Malleable & 5 & 2 & 0 & 0 & 1 & 0 \\
\hline Roleplay & 2 & 1 & 2 & 0 & 0 & 3 \\
\hline Light room & 1 & 0 & 0 & 0 & 0 & 1 \\
\hline Construction & 3 & 0 & 0 & 1 & 0 & 0 \\
\hline Construction resources & 0 & 1 & 0 & 1 & 0 & 0 \\
\hline Literacy resources & 1 & 0 & $\mathbf{0}$ & 0 & 0 & 0 \\
\hline Literacy tables & 3 & 0 & 1 & 1 & 2 & 2 \\
\hline Computers & 1 & 0 & 1 & 1 & 0 & 2 \\
\hline Reading area & 2 & 0 & 1 & 0 & 0 & 1 \\
\hline Numeracy & 1 & 0 & 0 & 1 & 0 & 1 \\
\hline Waterplay & 1 & 1 & 0 & 0 & 0 & 1 \\
\hline Creative & 1 & 2 & 0 & 1 & 0 & 1 \\
\hline Bay adjoining IW & 3 & 1 & 0 & 0 & 0 & 0 \\
\hline In front of IW & 5 & 1 & 0 & 1 & 1 & 1 \\
\hline Snack area & 0 & 0 & 0 & 0 & 1 & 0 \\
\hline Outside & 0 & 4 & 0 & 0 & 3 & 3 \\
\hline Guinea pigs & 0 & 0 & 0 & 0 & 1 & 0 \\
\hline Other e.g. between areas & 7 & 1 & 0 & 0 & 4 & 6 \\
\hline
\end{tabular}

Table 1

\section{Using video data to evaluate the physical environment}

An advantage of using video is that it is possible watch the video several times including slow motion and cropped perspectives, which supports an iterative experiential journey. The following section illustrates this reflective encounter, 'turning towards' one evocative object i.e. children at the fine sand area.

A micro analysis of 20 seconds of video involved watching the full speed video several times as well as watching cropped and slow motion versions. The corresponding photo analysis represents both the researcher's response to the video data and comments from teachers and student teachers elicited when watching the video. The reader is advised to watch the videos a few times and to use the MySQL database to record and explore generated meanings including those of other readers before continuing to read the following section. (Login and password for all multimedia - login: messy1 password: messy1) Normal speed: - http://eyle.org/EN_S1/sand1.html (http://eyle.org/EN S1/sand1.html) Slow motion video: - http://eyle.org/Slow/slow.mp4 
Although more recent research (Howes \& Matherson, 1992; Howes, 1980; Smith, 1978) has suggested that Parten's play types (Parten, 1932) may reflect increasing involvement in play activity rather than being a predictive indicator of a developmental sequence related to social competence, Parten's categories can still be a useful starting point when observing children's play. Parten's leadership styles (1933) also continue to be useful for adding a further dimension when observing children.

Figure 2

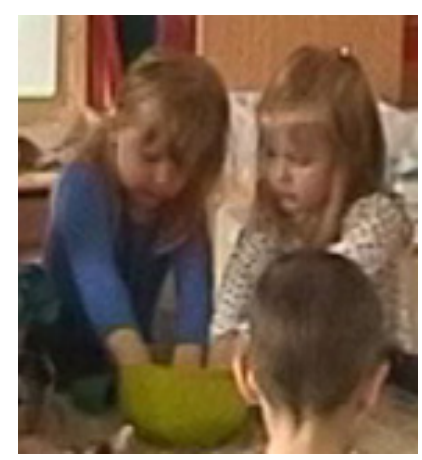

Contrasted with the seven other children who were attracted to the fine sand area and who are occupied with their own activity, two of the girls appear to be playing together as they have their hands in a plastic bowl (fig 2). The girls appear to value being together and there is a moment when one observes the action of the other. There is also an element of turn taking as one waits responsively before using a large plastic spoon. This seems to be a form of associative play rather than collaborative play as the girls' interest appears to be more in being together rather than in the activity as such. Parten (1932) refers to associative play as "group play in which there is overt recognition by the group members of their common activity, interests, and personal associations" ( $p$. 250) but where the interest is primarily in the association rather than the activity.

Each of the other five children standing around the sand area appears to be occupied in their own way. This gives the impression of parallel play though the children clearly notice actions and events as they happen. For example, the boy on the left (LC) seems to watch the girl on the right for a brief moment before continuing with his own interest (fig. 3). This is clearly reflected by the observations of Parten (1932) who identified play in the sand area as a typical example of parallel play 
Figure 3

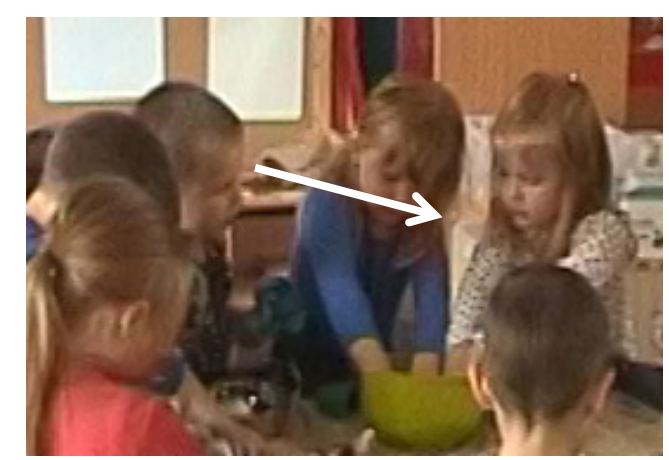

"Several children stand close to one another around the sandbox, each child going after and using the toys with which he wishes to play in the sand (usually cups). Children come and go all the time, but those remaining at the sandbox pay no attention to the movements of others; they are absorbed in their own activities." (Parten 1932 p. 250)

A cropped view of children on the left of the table helps focus attention on LC. Despite the bold movements of JD to reach out across the sand table, LC is clearly following his own interest and reaches in front of JD to retrieve an implement Fig 4). The hand of LC is just visible reaching under the arm of JD. There is a sense of no waiting as each of the children is self-absorbed in their own activity.

Figure 4

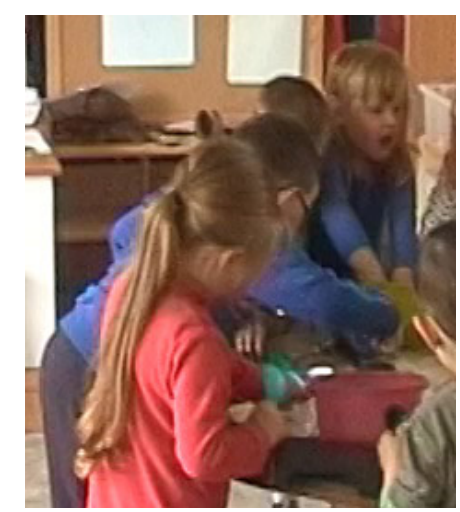


As JD reaches out to the bowl the girl on the right (GR) responds by looking intently at JD for a brief moment (fig. 5). At this point it becomes possible to speculate about the action: Why does GR look so intently at JD? Is JD encroaching on the activity of the two girls? Even after JD has withdrawn his hand GR continues looking. Is she trying to attract JD's attention to see if he wants to join in with the two girls?

Figure 5

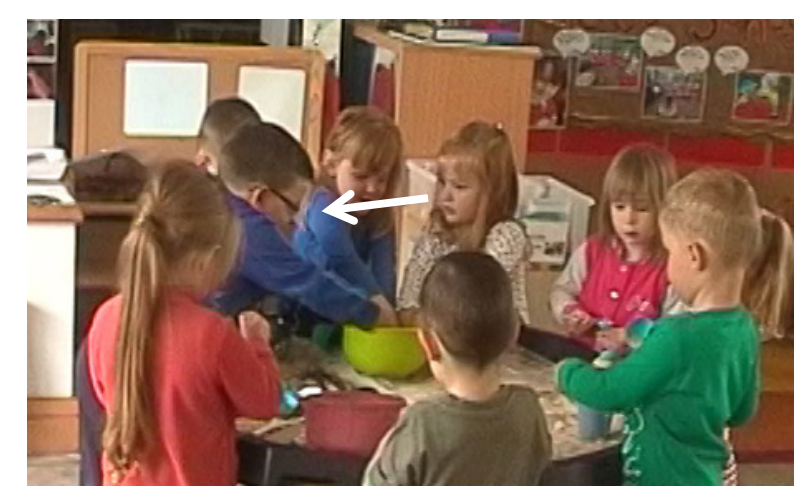

As the action develops JD reaches into the bowl again and takes some sand. This time he allows the sand to pour through his fingers and four of the other children watch closely as this happens.

Figure 6

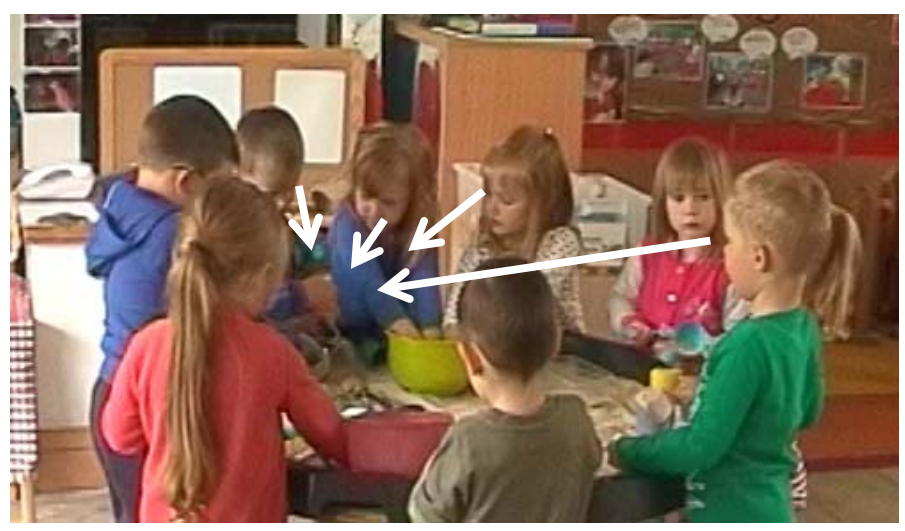

By now it is noticeable that JD seems slightly more animated than the other children. Although all the other children are active JD's movements are bigger, fuller body movements. He seems more interested in reaching across the table whereas the others stand around the table and even use the table for support. Is this a significant difference between JD and the others? 
The cropped image focusing on the right side of the table shows the boy on the far right (AD) leaning against the table with the right leg slightly raised, concentrating on pouring sand and a spherical object from one container into another (fig. 7). The concentration involved suggests the epistemic nature of this action. Is $A D$ developing mastery and control or exploring what will happen to the spherical object (Andrews, 2012) and can any significance be attached to AD's leaning against the side of the sand area? Observations from visits on other days show AD using the physical environment as a support e.g. leaning against the wall and against a partition screen.

\section{Figure 7}

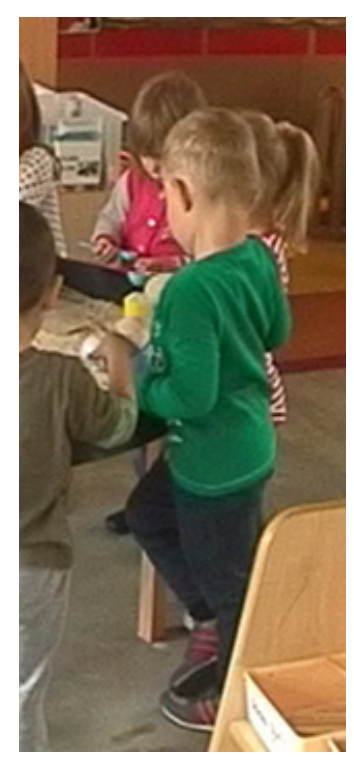

Close observation of the girl on the far right (IZ) shows that throughout the sequence she never looks towards the bowl or JD but watches the girl next to AD which suggests this is onlooker play (Parten, 1932) though this soon gives way to participation when IZ starts to copy the tapping movement. Although there is no leadership in this assemblage of children $\mathrm{IZ}$ is 'following' rather than engaging in an independent pursuit or directing style (Parten, 1933). An observation from later the same day shows IZ in the water play area tapping rhythmically with a fishing rod which suggests a 'tapping' schema.

The other two children continued to focus intently on their own activity throughout the duration of the video clip and beyond as this sand play occupied the children for an extended period of time. AD (boy on far right) found this area particularly interesting and was observed returning to the sand at 
different times of the day. On one occasion he and a few other children walked around the sand tray running their hands through the sand. On another occasion AD was by himself exploring the sand. The nursery staff decided to keep this area for longer than usual (about two weeks) because it continued to interest and engage the children.

\section{Drawing the threads together}

Turning away from the specific details of the sand play observations to generate broader themes, this sand play was just one moment in a whole range of planned and unplanned learning experiences as children encountered the physical environment throughout the day. What made this such a popular area? The practitioners' views recorded on the MySQL database included the "...area changes frequently so attracts interest because it's different" and "offers sought after sensory experiences". Particularly in relation to AD, a Polish boy with EAL at Stage 1 (Read 2012), one teacher added the general comment, "He likes sensory experience... this is calming". The new experience of touching and feeling very fine sand which although appearing solid, flows unexpectedly through the fingers was also a source of wonder and interest.

One of the children can be heard singing out, "Let's get messy!" - the only voice - perhaps attributable to the number of Stage 1 EAL children at the sand area, talk was conspicuous by its absence but close observation revealed an interweaving of body movements and children observing and responding to each other. Messy play can have a particular appeal for EAL children who speak very little English. As Duffy (2007) noted,

"It offers [children new to a setting] a way to become involved and get to know other children. As this sort of play does not rely on words, children who are in the process of acquiring English as an additional language can join in and use the materials with their peers. There is no 'right' way to play with cornflower or dough and children with special needs and 
disabilities are able to use these open-ended materials in their own way as part of the group." (p. 2)

Messy play or Fleming's (1996) vivid categorisation which contrasts orgiastic play with acetic play suggests an indulgent sploshing around in puddles or dipping hands in paint. Nonetheless, the way in which "Let's get messy" rings out suggests that at least for this particular child it was time to have some fun... with a hint of previous experience of having fun included for good measure! Of course, the expression of boundless energy, exploring the mystery of crawling under tables or experiencing the tackiness of glue on the fingers, and then fingers in contact with objects and furniture are only a part of what it means to be a child. Yet standing back, this sand play seemed to be characterised more by restrained involvement as children stood round the edges than by a release of the energies of childhood (Barnett 2014). An image of Foucault's docile bodies comes into view (Foucault 1977) amidst a noticeable absence of detailed regulation and surveillance. Although there is some imposed structure as when the lead teacher gains the attention of all the children to introduce an activity, and when practitioners monitor and record evidence of children's progress, partitioning and the daily programme give ground to children's free flow and choosing time, particularly in Reggio inspired settings. The predominant child initiated activities are self-regulated and the cultivated play of the three and half year olds is already well developed. It seems that the affordances of the areas and resources suggest possibilities and encourage particular forms of play. The physical environment itself takes on the role of zones of proximal development (Lippman 2002, 2004) and performs the function of a 'third teacher' (Thornton \& Brunton 2005). Though as Cannella (1999 p. 41) notes "the illusion of choice providing alternatives within a narrow vision for teachers and an even narrower field for children" is potentially more insidious than more direct control of behaviour, as choices although free are encompassed by the adult values underpinning the design of the setting. Yet children seek the company and support of practitioners who in turn encourage and help children in their pursuits. Interesting in this respect are the children's trays where one of the children kept his Spiderman doll until home time - a noticeable separation of the child's world from the pre-school setting though soon enough the tray started to contain items made during the day for mum. 
One of the teachers noted that the water play area, which had been resourced with fishing rods, wasn't particularly successful as it provided limited scope for creativity and didn't appeal to the children so was rapidly replaced with a more engaging alternative. Back at the find sand area however the children appeared confident and there was sustained involvement. This was a new experience with manipulable materials perhaps supported by a sense of stability preserved by the teaching staff maintaining the general character of the multiple areas within the setting. Teaching staff identified several signs of the Characteristics of Effective Learning (EYFS 2012) in this popular area e.g. being involved and concentrating, finding out and exploring, having their own ideas, expressive arts and design and realising tools can be used for a purpose. The responsiveness of the staff to children's play preferences was reflected in one of the contributions to the MySQL database,

"The sand area was kept out for a long time because it was so popular with different resources being added and children adding their own resources. Even after ten minutes children would replace resources with their own choices."

Author's email for correspondence: a.barnett@worc.ac.uk

\section{References:}

Barnett, A (2013) Developing a Creative Analytic Paradigm, PhD thesis, University of Worcester. Available from: https://eprints.worc.ac.uk/3089/

Barnett, A (2014) Generative divergent analysis as a model for reflection illustrated with reference to an early-years reception class and wicker settee. Reflective Practice. 15 (4) 518-529

Baker, A. C., Jensen, P. \& Kolb, D. (2002) Conversational learning: An experiential approach to knowledge creation [Online] Available from: http://learningfromexperience.com/researchlibrary/conversation-as-experiential-learning/ [Accessed 16/2/2012] 
Baker-Jones, S (2010) Early Years Schemas, Accessed from:

http://www.sennenpreschool.org.uk/uploads/5/4/5/9/5459458/early years schema2 copy.pdf

Cannella, G (1999) The Scientific Discourse of Education: predetermining the lives of others -

Foucault, education, and children, Contemporary Issues in Early Childhood, 1(1) pp. 36-44

Duffy, B (2007) All About ...Messy Play

http://www.ndna.org.uk/Resources/NDNA/Generic\%20Folders\%202/10/25.\%20EYFS\%20all\%20abo

ut\%20messy\%20play.PDF Accessed: 10-2-2015

Fleming, D. (1996) Powerplay: toys as popular culture, Manchester, Manchester University Press.

Gordon, R., Fujimoto, K., Kaestner, R., Korenman, S \& Abner, K (2013) An Assessment of the Validity of the ECERS_R With Implications for Measures of Child Care Quality and Relations to Child Development, Developmental Psychology, 49(1) pp. 146-160

Heath, C., Hindmarsh, J \& Luff, P (2010) Video in qualitative research, London, Sage

Howes, C (1980) Peer Play Scale as an Index of Complexity of Peer Interaction, Developmental Psychology, 16(4) pp. 371-372

Howes, C \& Matheson, C (1992) Sequences in the Development of Competent Play With Peers: Social and Social Pretend Play, Developmental Psychology, 28(5) pp. 961-974

Howes, C \& Stewart, P (1987) Child's Play With Adults, Toys, and Peers: An Examination of Family and Child-Care Influences, Developmental Psychology, 23(3) pp. 423-430

Laevers, F., Daems, M., De Bruyckere, G., Declercq, B., Moons, J., Silkens, K., Snoeck, G. \& Van Kessel, M (2005) Sics (Zlko) Flanders, Kind \& Gezin and Research Centre for Experiential Education

Layzer, J \& Goodson, B (2006) The "Quality" of Early Care and Education Settings: Definitional and Measurement Issues, Evaluation Review, 30 pp. 556-576 
Lippman, P. (2002) Understanding Activity Settings in Relationship to the Design of Learning

Environments. The Quarterly Newsletter of the Committee on Architecture for Education PIA, 3, 1-9.

Lippman, P. (2004) Advancing Concepts about Activity Settings within Learning Environments. CAE Net Quarterly Newsletter for the Committee on Architecture for Education PIA, 1-13.

Parten, M (1932) Social participation among pre-school children, Journal of Abnormal and Social Psychology 27(4) pp. 243-269

Parten, M (1933) Leadership among preschool children, Journal of Abnormal and Social Psychology 27(3) pp. 430-440

Rasberry, G, W (2002) Imagine, Inventing a Data-Dancer. In Bagley, C \& Cancienne, M, B (eds.)

Dancing the data, New York, Peter Lang

Read, A (2012) 'Good practice’ for pupils with English as an additional language: patterns in student teachers' thinking, Research in Teacher Education, 2 (2) pp. 24-30. Accessed from:

http://www.uel.ac.uk/wwwmedia/microsites/riste/Article-Andrew-read-p24-30.pdf Accessed 21-22015

SSAT (2014) http://complexld.ssatrust.org.uk/project-resources/engagement-profile-scale.html

Smith, P (1978) A Longitudinal Study of Social Participation in Preschool Children: Solitary and Parallel Play Reexamined, Developmental Psychology, 14(5) pp. 517-523

Thornton, L \& Brunton, P (2005) Understanding the Reggio approach: reflections on the early childhood experience of Reggio Emilia, London, David Fulton

Walsh, G. \& Gardner, J. (2005) Assessing the Quality of Early Years Learning Environments Early Childhood Research and Practice [Online] 7, 1, Available from: http://ecrp.uiuc.edu/v7n1/walsh.html [Accessed 22/2/2015] 
Williams, M., Dicks, B., Coffey, A \& Mason, B (no date) Qualitative data archiving and reuse: mapping the ethical terrain Available from:

http://www.cf.ac.uk/socsi/hyper/QUADS/Briefing\%20paper\%20ethics.pdf Accessed 22/2/2015 